\title{
Potentiostatic Electrochemical Preparation and Characterisation of Aluminium Containing Nickel Selenide
}

\author{
SANDEEP GOHAR ${ }^{*}$ and R.K. PATHAK \\ *Department of Chemistry, Govt.Holkar Science College, Indore - 452 001, India. \\ Department of Chemistry, Govt.MLB P.G. girls College, Indore - 452 006, India. \\ ${ }^{*}$ Corresponding author E-mail: sandeep.gohar@gmail.com
}

http://dx.doi.org/10.13005/ojc/290424

(Received: August 18, 2013; Accepted: October 29, 2013)

\begin{abstract}
The wide range of properties exhibited by Al based alloy makes them suitable for different applications. Aluminium containing nickel Selenide ternary alloy possess considerable corrosion resistance as compared to their pure metal counterparts. The objective of the present work has been focused on the preparation and characterisation of its thin film. Alloying with Aluminium improve the oxidation resistance and increases the heat conductivity of the alloy. There is always a high demand for plating $\mathrm{Al}$ and its alloys in automotive and aerospace products, house-hold goods, and artificial jewellery etc,. The morphological and the structural studies of the electrodeposited thin film were determined by Scanning Electron Microscope (SEM) images and X-Ray Diffraction Pattern (XRD) while elemental composition has been done by Energy Dispersive X-Ray Spectroscopy (EDAX analysis).
\end{abstract}

Key words: Electrodeposition, Corrosion Rate, Film-Thickness, SEM, XRD, EDAX analysis.

\section{INTRODUCTION}

Intermetallic aluminides of transition metals such as nickel exhibit advantageous properties like high tensile strength, low density and corrosion resistance at high temperature ${ }^{1-2}$. Therefore these materials can be investigated for their possible use as high-temperature structural materials. Moreover, transition metal aluminides have sufficient aluminium content to form an adherent alumina layer on the surface when exposed to air or oxygen atmospheres ${ }^{3}$ leading to excellent oxidation resistance in these intermetallic compounds. Although the electrodeposition of $\mathrm{Al}$ metal in aqueous solutions is rather difficult because of the high electropositivity of Al, some authors were successful in fabricating Ni-Al composite coatings on various substrates through electrodeposition under proper conditions ${ }^{4-8}$. Properties of electrolytic nickel coatings are well known. Their wide application is a result of specific properties of nickel, which exhibit good corrosion resistance in aggressive solutions and also high catalytic activity for many electrochemical processes, in particular for the hydrogen evolution reaction ${ }^{9-13}$. Most work on mechanical properties of coatings system has been focused on the influence 
of the coating on the substrate properties, such as stress rupture ${ }^{14-15}$. Electrodeposition technique has the merits of simple processing, cost effectiveness and good compositional control to prepare thin films like Aluminium containing Nickel Selenide.

\section{EXPERIMENTAL}

The reagents used consist of Nickel Sulphate Heptahydrate, Aluminium Potassium Sulphate, Selenium dioxide and Boric acid. All the reagents used were of Analytical Grade. The electrochemical assembly consists of a conventional three-electrode assembly. Titanium electrode $(1 \mathrm{~cm}$ $\times 1 \mathrm{~cm}$ ) served as a counter electrode, saturated calomel electrode (SCE) was used as a reference electrode and the mild steel substrate $(1 \mathrm{~cm} \times 1 \mathrm{~cm})$ was used as a working electrode. The thin film of Aluminium containing Nickel Selenide ternary alloy was potentiostatically electrodeposited at $-0.6 \mathrm{~V}$ Vs SCE. The deposition was carried out for a period of 30 minutes. For data acquisition transistor based power supply unit Model 613 (systronics electronics limited) and multimeters were used for the measurement of current and potential during electrochemical codeposition. Three different solutions were prepared by taking $\mathrm{NiSO}_{4} \cdot 7 \mathrm{H}_{2} \mathrm{O}, \mathrm{AlK}\left(\mathrm{SO}_{4}\right)_{2} \cdot 12 \mathrm{H}_{2} \mathrm{O} \mathrm{H}_{3} \mathrm{BO}_{3}$ and $\mathrm{SeO}_{2}$ and one solution containing $\mathrm{NiSO}_{4} .7 \mathrm{H}_{2} \mathrm{O}, \mathrm{H}_{3} \mathrm{BO}_{3}$ and $\mathrm{SeO}_{2}$ was prepared. All these solutions were prepared in deionised water. The bath temperature was constantly maintained at $40 \pm 2^{\mathrm{R}} \mathrm{C}$ while $\mathrm{pH}$ was adjusted at 3.0 by adding dilute sulphuric acid. The SEM images and EDAX of the electrodeposited samples were obtained by SEM instrument model JEOL JSM 5600 while $X$ ray diffraction pattern (XRD) of the samples were obtained by X-ray diffractometer D8 Advance Bruker AXS.

\section{RESULTS AND DISCUSSION}

In the present work thin film of Aluminium containing Nickel Selenide ternary alloy is prepared by the electrodeposition process. For codeposition of two of more ionic species their simultaneous discharging is essential. Since the deposition potential of Nickel, Aluminium and Selenium is different therefore to estimate the common potential domain within which the deposition of these three ions occurs, their Current-Voltage behaviour in the electroplating solutions was studied. Current-Voltage curve (Fig.1) clearly indicates that the deposition of these ions can be done at $-0.6 \mathrm{~V}$ Vs SCE. Before applying requisite potential the electrodes were dipped in electroplating solution for about 5-10 minutes so as to establish equilibrium. Once equilibrium is established the potential was applied. When the deposition was carried out potentiostatically, initially the current value was high which attains a time invariant value.

Table 1: Testing of electrodeposited thin films in experimental solutions of different Concentrations

\begin{tabular}{|c|c|c|c|c|c|c|}
\hline $\begin{array}{l}\text { Electroplating } \\
\text { solution }\end{array}$ & $\begin{array}{l}\text { Experimental } \\
\text { solution } \\
\mathrm{H}_{2} \mathrm{SO}_{4}\end{array}$ & $\begin{array}{l}\text { Corrosion } \\
\text { Rate } \\
\left(10^{-4} \mathrm{mpy}\right)\end{array}$ & $\begin{array}{l}\text { Experimental } \\
\text { solutionHCl }\end{array}$ & $\begin{array}{l}\text { Corrosion } \\
\text { Rate } \\
\left(10^{-4} \mathrm{mpy}\right)\end{array}$ & $\begin{array}{l}\text { Experimental } \\
\text { solution } \\
\mathrm{NaCl}\end{array}$ & $\begin{array}{l}\text { Corrosion } \\
\text { Rate } \\
\left(10^{-4} \mathrm{mpy}\right)\end{array}$ \\
\hline $\mathrm{Ni}(0.1 \mathrm{M})+$ & $0.1 \mathrm{~N} \mathrm{H}_{2} \mathrm{SO}_{4}$ & 14.0 & $0.1 \mathrm{~N} \mathrm{HCl}$ & 7.74 & $1 \% \mathrm{NaCl}$ & 8.48 \\
\hline $\mathrm{Se}(0.01 \mathrm{M})+$ & $0.01 \mathrm{~N} \mathrm{H}_{2} \mathrm{SO}_{4}$ & 2.44 & $0.01 \mathrm{~N} \mathrm{HCl}$ & 1.9 & $0.01 \% \mathrm{NaCl}$ & 2.62 \\
\hline $\mathrm{Al}(0.01 \mathrm{M})$ & $0.001 \mathrm{~N} \mathrm{H}_{2} \mathrm{SO}_{4}$ & 2.18 & $0.001 \mathrm{~N} \mathrm{HCl}$ & 0.97 & $0.001 \% \mathrm{NaCl}$ & 2.03 \\
\hline $\mathrm{Ni}(0.1 \mathrm{M})+$ & $0.1 \mathrm{~N} \mathrm{H}_{2} \mathrm{SO}_{4}$ & 9.3 & $0.1 \mathrm{~N} \mathrm{HCl}$ & 2.44 & $1 \% \mathrm{NaCl}$ & 2.44 \\
\hline $\mathrm{Se}(0.01 \mathrm{M})+$ & $0.01 \mathrm{~N} \mathrm{H}_{2} \mathrm{SO}_{4}$ & 1.98 & $0.01 \mathrm{~N} \mathrm{HCl}$ & 1.54 & $0.01 \% \mathrm{NaCl}$ & 1.54 \\
\hline $\mathrm{Al}(0.05 \mathrm{M}$ & $0.001 \mathrm{~N} \mathrm{H}_{2} \mathrm{SO}_{4}$ & 1.77 & $0.001 \mathrm{~N} \mathrm{HCl}$ & 1.69 & $0.001 \% \mathrm{NaCl}$ & 1.17 \\
\hline $\mathrm{Ni}(0.1 \mathrm{M})+$ & $0.1 \mathrm{~N} \mathrm{H}_{2} \mathrm{SO}_{4}$ & 2.56 & $0.1 \mathrm{~N} \mathrm{HCl}$ & 3.2 & $1 \% \mathrm{NaCl}$ & 1.94 \\
\hline $\mathrm{Se}(0.01 \mathrm{M})+$ & $0.01 \mathrm{~N} \mathrm{H}_{2} \mathrm{SO}_{4}$ & 1.06 & $0.01 \mathrm{~N} \mathrm{HCl}$ & 1.37 & $0.01 \% \mathrm{NaCl}$ & 1.40 \\
\hline $\mathrm{Al}(0.10 \mathrm{M}$ & $0.001 \mathrm{~N} \mathrm{H}_{2} \mathrm{SO}_{4}$ & 0.9307 & $0.001 \mathrm{~N} \mathrm{HCl}$ & 0.93 & $0.001 \% \mathrm{NaCl}$ & 1.37 \\
\hline $\mathrm{Ni}(0.1 \mathrm{M})+$ & $0.1 \mathrm{~N} \mathrm{H}_{2} \mathrm{SO}_{4}$ & 8.56 & $0.1 \mathrm{~N} \mathrm{HCl}$ & 8.56 & $1 \% \mathrm{NaCl}$ & 3.10 \\
\hline \multirow[t]{2}{*}{$\mathrm{Se}(0.01 \mathrm{M})$} & $0.01 \mathrm{~N} \mathrm{H}_{2} \mathrm{SO}_{4}$ & 2.10 & $0.01 \mathrm{~N} \mathrm{HCl}$ & 2.15 & $0.01 \% \mathrm{NaCl}$ & 2.77 \\
\hline & $0.001 \mathrm{~N} \mathrm{H}_{2} \mathrm{SO}_{4}$ & 1.02 & $0.001 \mathrm{~N} \mathrm{HCl}$ & 0.98 & $0.001 \% \mathrm{NaCl}$ & 2.46 \\
\hline
\end{tabular}




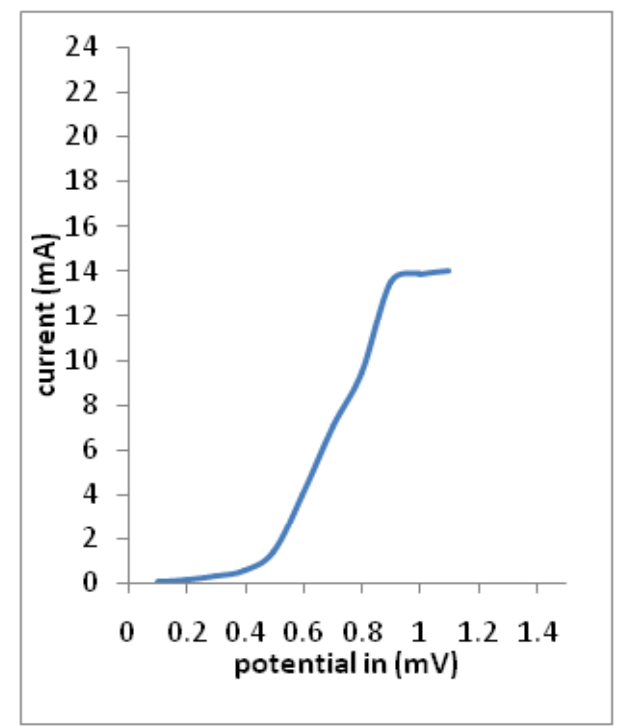

Fig.1: Current Vs Potential

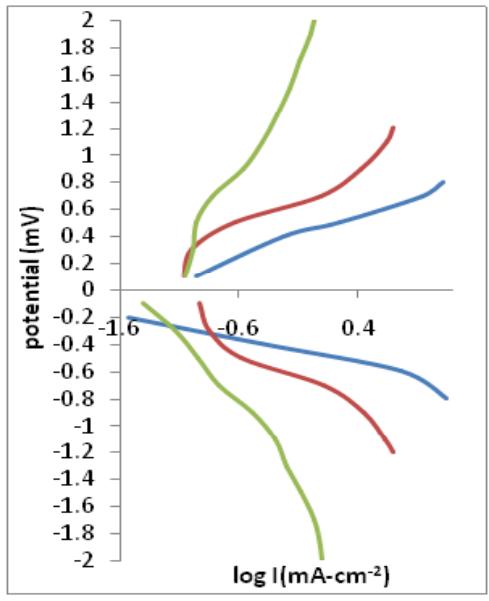

Fig. 3: Logl Vs Potential

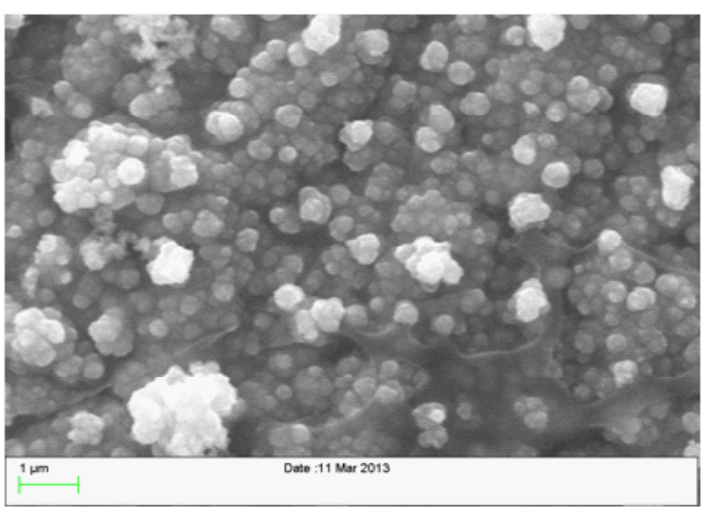

Fig. 5: SEM Image of NiAISe thin film

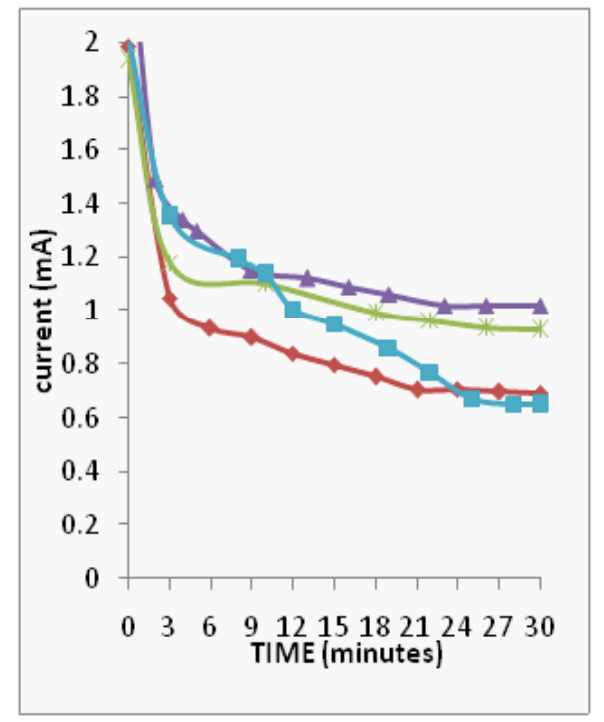

Fig. 2: Current Vs Time

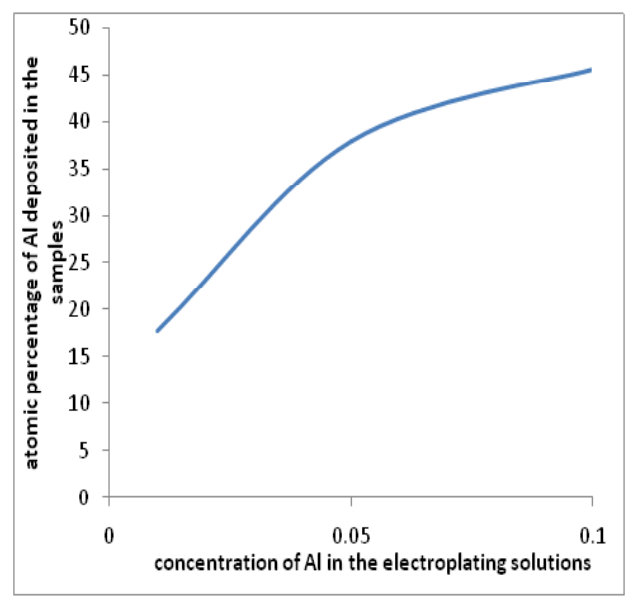

Fig. 4: Atomic Percentage of Cadmium in thin film Vs Concetration of cadmium in electroplating solution

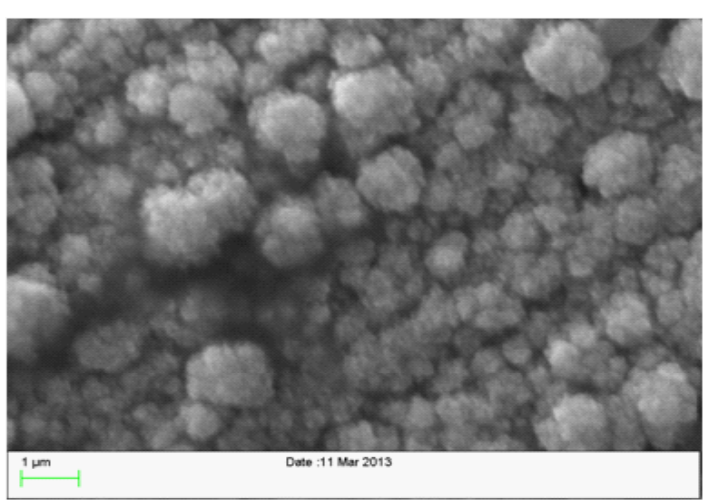

Fig. 6: SEM Image of NiSe thin film 


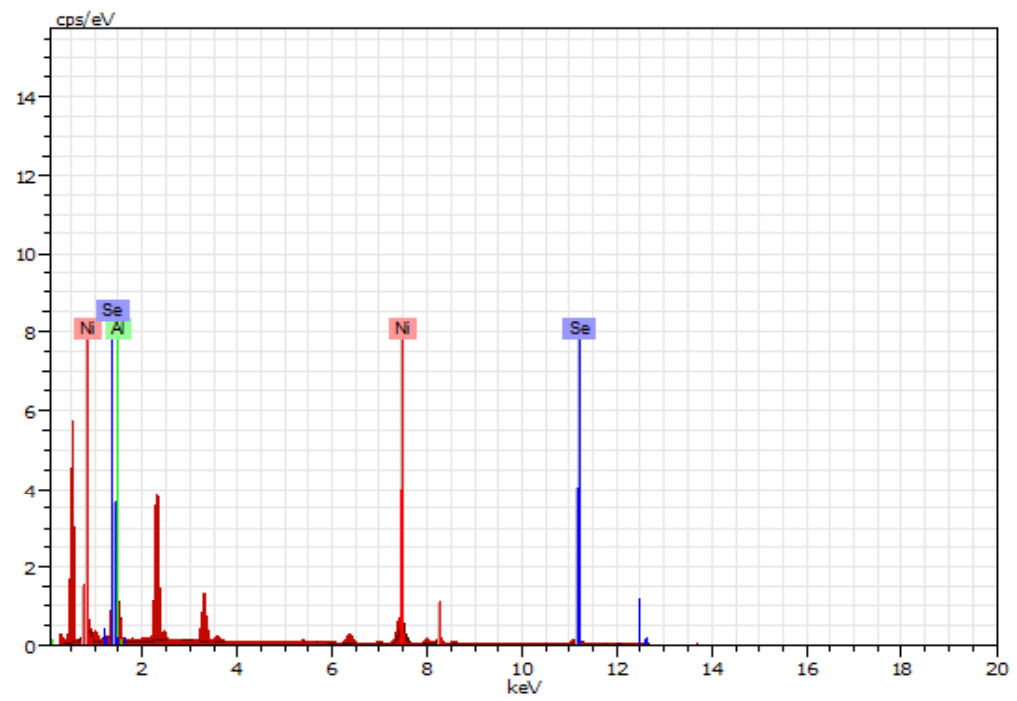

Fig. 7: Representative EDAX of NiAISe thin film

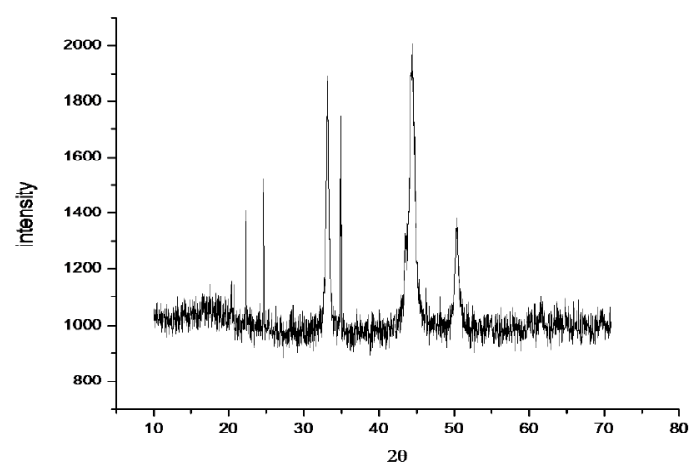

Fig. 8: A Representative XRD of NiAISe thin film

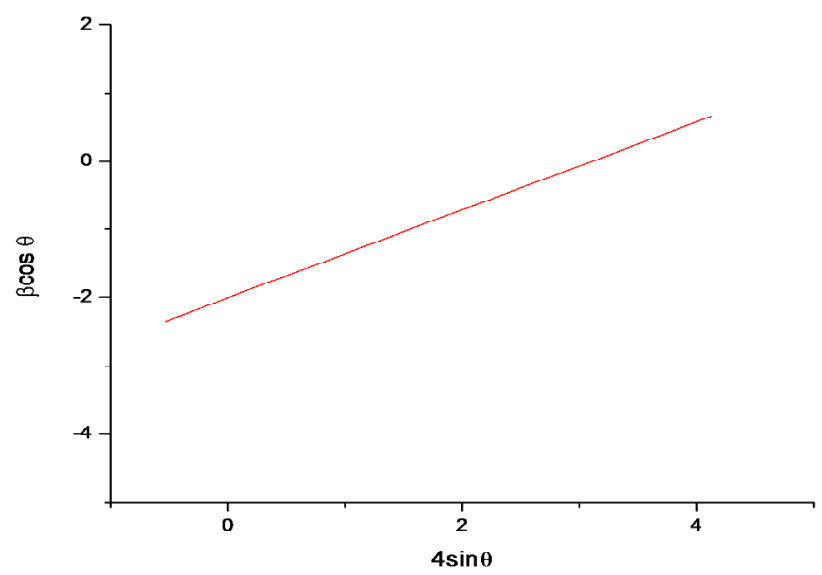

Fig. 9: A Representative Williamson Hall Plot 
The area under the Current-Time curve is used to calculate the thickness of the deposited thin film (Fig.2).The thickness of the samples was found to lie between $7.1 \times 10^{-6}$ to $11.9 \times 10^{-6} \mathrm{~cm}^{-1}$. Thickness of thin film prepared from electroplating solution of composition $\mathrm{Ni}(0.1 \mathrm{M})+\mathrm{Se}(0.01 \mathrm{M})+\mathrm{Al}(0.01 \mathrm{M})$ was lesser than the thin film deposited from the solution of composition $\mathrm{Ni}(0.1 \mathrm{M})+\mathrm{Se}(0.01 \mathrm{M})+\mathrm{Al}(0.05 \mathrm{M})$ while, the thickness of thin film deposited from the solution having $\mathrm{Ni}(0.1 \mathrm{M})+\mathrm{Se}(0.01 \mathrm{M})+\mathrm{Al}(0.10 \mathrm{M})$ was maximum. The thickness of thin film prepared from solution containing $\mathrm{Ni}(0.1 \mathrm{M})+\mathrm{Se}(0.01 \mathrm{M})$ i.e., the electroplating solution without aluminium ions was compared with all the above mentioned compositions, it is found to be least in its thickness. Boric acid is used in all the electroplating solutions. It is believed that boric acid either complexes with $\mathrm{Ni}^{2+}$ ions, acting as a homogeneous catalyst or adsorbs on the electrode surface and has a significant role in morphology and compositional characteristics. The presence of boric acid results in an increase of current efficiency of deposition process, amount of the deposited alloy, and nucleation density of the deposit. Also, boric acid acts as a buffer to maintain $\mathrm{pH}$ of the electrolyte bath. After electrosynthesizing the thin films all the samples were tested in different corroding solution of $\mathrm{HCl}, \mathrm{H}_{2} \mathrm{SO}_{4}$ and $\mathrm{NaCl}$ having different concentration. The cathodic polarisation and anodic polarisation data were obtained which in turn were used to construct Tafel Plot (Fig.3). A small plateau is observed in the Tafel Plot which could be associated with the accelerated passivation process. Corrosion rate was determined by the equation

$$
\mathrm{CR}(\mathrm{mpy})=\frac{0.13 \times \mathrm{I}_{\text {corr }} \times \mathrm{E}_{\mathrm{w}}}{\mathrm{F} \times \mathrm{d} \times \mathrm{A}}
$$

Where,

CR $(m p y)=$ Corrosion rate in milli inches per year, $F$ = Faraday's constant, $d=$ density of deposited alloy, $A=$ Area of electrodes.

As the aluminium confers better corrosion resistance to the coatings therefore the concentration of Nickel and Selenium is same in all the solution but the concentration of aluminium is gradually increased in the plating solutions. Corrosion testing of the thin films is done in $0.1 \mathrm{~N} \mathrm{HCl}, 0.01 \mathrm{~N} \mathrm{HCl}$, $0.001 \mathrm{~N} \mathrm{HCl}, 0.1 \mathrm{~N} \mathrm{H}_{2} \mathrm{SO}_{4}, 0.01 \mathrm{~N} \mathrm{H}_{2} \mathrm{SO}_{4}, 0.001 \mathrm{~N}$ $\mathrm{H}_{2} \mathrm{SO}_{4}, 1 \% \mathrm{NaCl}, 0.01 \% \mathrm{NaCl}, 0.001 \% \mathrm{NaCl}$ solutions respectively. The corrosion rate of the thin films decreases with increase in the amount of aluminium ion concentration in the electrolytic solution. Hence corrosion resistance increases with the higher concentration of aluminium in the deposited thin films (Table.1). These results clearly indicate the increased atomic percentage of the aluminium in the electrodeposits along with increase in its concentration in the electroplating solutions (Fig.4). The morphological studies were carried out by SEM images. The electrodeposited thin films prepared from the different electroplating solutions adhere well to the mild steel substrate. Some of the SEM images of the deposited thin film are shown (Fig.5-6). It shows that the thin films are composed of largely regular-shaped grains. The grains tend to cover the substrate surface completely. This is due to several crystallites grouped together to form larger grains. Figure 7 shows the EDAX analysis of the electrodeposits. The EDAX analysis confirms the inclusion of Nickel, Aluminium and Selenium in the deposited thin films. From EDAX analysis atomic percentage of deposited elements is obtained. A representative $\mathrm{XRD}$ of the electrodeposited thin films is shown in Fig.8. The XRD patterns of all the samples were indexed successfully to determine the crystal structure, grain size and surface stress in the sample. The peaks obtained in the XRD pattern were compared with the reference pattern in the JCPS card standard peaks. The crystal structure was found to be cubic. XRD of the samples indicates polycrystalline nature of the thin films. The grain size is determined by Scherer equation which was found to be lesser than 100nm.The microstrain induced on surface of thin film can be attributed to crystal imperfection and distortion. A representative Williamson's Hall plot is shown in fig.9. The growth of internal stresses in the electrodeposited thin film is determined by it. In some samples the slopes were found be negative indicating compressive stress while in some cases it was positive indicating tensile stress.

\section{CONCLUSION}

On the basis of current-voltage data derived from the cathodic and anodic polarisation Tafel plots were constructed for determining the corrosion rate. The corrosion rate of the samples was found to decrease with the increase in the concentration of Aluminium in the electroplating solution. The 
deposition of Nickel, Aluminium and Selenium in the thin films is confirmed by XRD \& EDAX of the samples. The XRD patterns recorded for the thin films shows polycrystalline nature with a cubical structure of the electrodeposited material. Morphological and structural details of the sample were revealed by the SEM. It shows that the thin films are composed of largely regular-shaped grains. The grains tend to cover the substrate surface completely. This is due to several crystallites grouped together to form larger grains. Grain size lies below 100nm, while the micro-strain in the samples was determined by equation given by Williamson Hall which indicates the presence of compressive stress in some samples and tensile stress in rest of the electrodeposits.

\section{ACKNOWLEDGEMENTS}

The authors express sincere thanks to Inter University Consortium, Indore for providing basic facilities and XRD analysis of the electrodeposited thin films. I acknowledge my thanks to Dr.Ruchita Pal of Advanced Instrumentation Research Facility Jawaharlal Nehru University, New Delhi for doing SEM and EDAX of sample in their laboratory.

\section{REFERENCES}

1. Baker, Munroe P. R., High temperature aluminides and intermetallics, Materials Research Society, Warrendale, Pennsylvannia, 425-457 (1990).

2. Brillo J., Bytchkov A., Egry I., Hennet L., Mathiak G., Pozdnyakova I., Price D.L., Thiaudiere D., Zanghi D., J. Non-Cryst. Solids 35: 4008-4012 (2006).

3. Deevi S.C., Sikka V.K., Intermetallics 4: 357375 (1996).

4. Susan D.F., Marder A.R., Acta Mater. 49: 1153-1163 (2001).

5. Susan D.F., Marder A.R., Oxid. Met. 57: 159180 (2002).

6. Zhou Y.B., Peng X., Wang F.H., Oxid. Met. 64: 169-183 (2005).

7. Liu H.F., Chen W.X., Surf. Coat. Technol. 191: 341-350 (2005)

8. Liu H.F., Chen W.X., Surf. Coat. Technol. 202: 4019-4027 (2008).
9. Lagiewka E., Budniok A., Niedbala J., Archives of Material science, 23: 137 (2002).

10. Niedbala J., Wykpisk., Budniok A., Lagiewka E., Archives of Material science, 23: 123 (2002).

11. Karimi - Shervedani R., Lasia A., J. Electrochem. Soc., 144: 511 (197).

12. Karimi - Shervedani R., Lasia A., J. Electrochem. Soc., 145: 2219 (1998).

13. Popczyk M., BajdurW., Galvanotechnik, 3(90): 662(1999).

14. Linde L., Internal Research. Report IM-2984 Swedish Inst. Met. Research. (1993).

15. Fairbanks J.W., Hecht R.J., Mat. Sci. Eng.. A88: 321 (1987).

16. K.K. Gupta, T. Kaur and Ekta Dadhich, Orient. J. Chem., 29(1): 177-180 (2013).

17. OmPrakash, S.A. lqbal and G. Jacob, Orient J. Chem., 29(3): 1079-1084 (2013). 